\section{Determination of the Velocity Constants in the Polymeriza- tion of Vinyl Compounds}

THE accepted mechanism for the polymerization of vinyl compounds involves four velocity constants : initiation $\left(k_{1}\right)$, chain propagation $\left(k_{2}\right)$, chain transfer $\left(k_{3}\right)$, and termination $\left(k_{k}\right)$. It is well known that standard methods of investigation give only two relations for the determination of these coefficients. In the absence of any transfer reaction, these relations determine $k_{1}$ and one of the ratios $k_{2} / k_{4}$, $k_{3} / k_{4}^{1 / 2}$ according to the order of the termination reaction. Melville has recently described a method which provides another relation values to be calculated under conditions such that transfer is unimportant.

We have found that when transfer is appreciable, it is possible to obtain two additiongl equations by studying the rate of change of viscosity of the liquid vinyl compound during and after irradiation. Thus it now becos four velocity becomes of the relations :

$$
\bar{P}=\frac{2 k_{2}}{2 k_{3}+k_{4}^{1 / 2}\left(k_{1}+A I\right)^{1 / 2}}, \cdot .
$$

$$
\begin{array}{r}
\frac{d \eta}{d t}=K_{m} M_{0} S^{2} \cdot \frac{k_{2}{ }^{2}}{k_{4}} \cdot \frac{k_{4}{ }^{1 / 2}\left(k_{1}+A I\right)^{1 / 2}}{k_{3}+k_{4}^{1 / 2}\left(k_{1}+A I\right)^{1 / 2}} \\
\left(1+\frac{k_{4}{ }^{1 / 2}\left(k_{1}+A I\right)^{1 / 2}}{k_{3}+k_{4}^{1 / 2}\left(k_{1}+A I\right)^{1 / 2}}\right) ;
\end{array}
$$

where $P$ is the mean degree of polymerization, $I$ the light intensity in arbitrary units, $A$ a constant, $\eta$ the speciflc viscosity corrected to in arbite dilution, $K_{m}$ the Standinger constant, and $M_{0}, S$ the molecular weight and concentration respectively of the monomer.

In these equations, allowance is made for the fact that the initial activation produces chains growing at both ends, while the transfer reaction leads to a chain which is active at one end only. Equations (1) and (2) provide three independent relations between the velocity constants. When the light is cut off, the concentration of active centres fails to its equilibrium value in the dark reaction. As a result there is a photochemical after-effect, of magnitude $\Delta \eta$, which for high light intensities is given by

$$
\begin{aligned}
\Delta \eta=K_{m} M_{0} S & \frac{k_{2}{ }^{2} k_{3}}{k_{1} k_{4}{ }^{2}\left(\beta^{2}-1\right)^{2}} \\
& \left(\beta^{2}-\beta+\left(\beta^{2}-3\right) \ln \frac{\beta+1}{2}\right), .
\end{aligned}
$$

where

$$
\beta=k_{3}\left(k_{1} k_{4}\right)^{-1 / 2}
$$

This provides the required fourth relation.

Incidentally, equation (2) indicates a simple means of determinin whether chain transfer is important, since in the absence of transfer $d \eta / d t$ is independent of light intensity.

This method has been applied to the polymerization of styrene a $25^{\circ} \mathrm{C}$. using light of wave-length $3000-4000 \mathrm{~A}$. In this case the aftereffect is sufficiently large to be measurable directly without the use of a sector. The values obtained were : $k,=6.0 \times 10^{-15}, k_{2}=4.5$, $k_{3}=1.3 \times 10^{-3}, k_{\mathrm{a}}=1.0 \times 10^{6}$ litre moles $^{-1} \mathrm{sec}^{-1}$. These flgures raise the following points :

(1) In the thermal (dark) polymerization, chain transfer, so far from being negligible, occurs about sixteen times as frequently as bimolecular termination. Thus from (1) the degree of polymerization is nearly $k, k$, and its variation with temperature is mainly determined by the value of $E_{3}-E_{3}$, and not by $E_{3}-\left(E_{1}+E_{4}\right)$, as has been previously assumed

(2) The apparent values of $k_{1}$ calculated by previous workers $\left(k_{1}{ }^{\prime}\right)$ may be shown to be given approximately by

$$
k_{1}^{\prime}=\frac{1}{2} k_{1}+k_{s} k_{1}{ }^{1 / 2} k_{\mathrm{a}}^{-1 / 2} \text {. }
$$

Here again the second term on the right predominates, and the activation energy previously calculated is not $E_{1}$ but $E_{3}+\frac{1}{2}\left(E_{1}-E_{6}\right)$

(3) The life of a growing chain is of the order of one minute.

4) The termination reaction is probably activated. Experiment to determine the energies of activation are in progress, and the method is being extended to other vinyl compounds. Full details will be published elsewhere in due course.

$$
\begin{aligned}
& \text { Courtaulds, Ltd., } \\
& \text { The Islet, } \\
& \text { Maidenhead Court, } \\
& \text { Maidenhead, } \\
& \text { Berks. } \\
& \text { April 4. }
\end{aligned}
$$

1 Burnett, G. M., and Melville, H. W., Nature, 156, 661 (1945) See, for example, Melville, H. W., Ann. Rep. Chem. Soc., 36, 61 (1939)。
Non-ideality in some Binary Hydrocarbon Systems

THE properties of non-ideal, binary, hydrocarbon mixtures are of interest both in connexion with the structure of liquids and with theories of solution, because in many of these systems there is little probability of chemical or dipole interaction. Data are available, however, for relatively few non-ideal hydrocarbon systems ${ }^{1}$ and the majority of these known systems consist of a saturated component
(paraffinic or cycloparaffinic) in admixture with an unsaturated or aromatic component.

It is therefore of interest that recent work in these laboratories, on liquid-vapour equilibrium at atmospheric pressure, has established the occurrence of marked non-ideality, including azeotrope formation in a series of four binary, paraffinic-cycloparaffinic (naphthenic) systems, systems in which both components are fully saturated bodies and in which azeotrope formation was hitherto unknown.

The first azeotropic system of this type to be detected was apparently that between cyclo minimum boiling minimum boiling azeotrope of boiling point $80.2^{\circ} \mathrm{C}$ (at $760 \mathrm{~mm}$.) containing $47 \cdot 5 \mathrm{~mol}$. per cent of cyclohexane (Fig. 1). The system cyclohexane-2.2-dimethylpentane forms a pseudo azeotrope over the concentration range 0-20 mol. per cent cyclohexane, such that the relative volatility ${ }^{3}$ in this region is unity and the boiling point substantially that of pure 2.2 -dimethylpentane $\left(79 \cdot 20^{\circ} \mathrm{C}\right.$. at $760 \mathrm{~mm}$.) Recently published work has revealed the existence of a minimumboling azeotrope in the system cyclohexane-2.2.3-trimethylbutan (triptane), containing $52 \cdot 2 \mathrm{~mol}$. per cent of cyclohexane and boiling results already obtained here.

other phown that no azeotrope is formed in the system methylcyclohexane-2.2.4-trimethylpentane ('iso-octare') but results obtained here indicate that although no azeotrope is formed

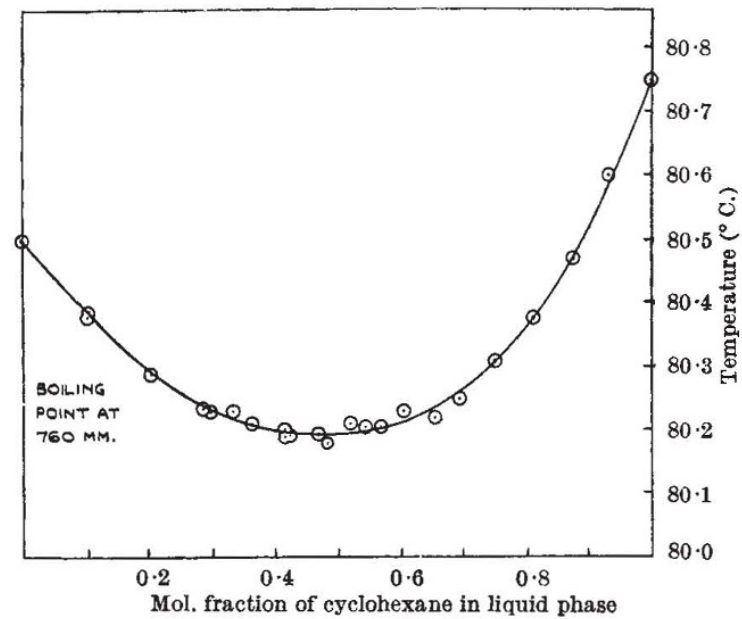

Fig. 1.
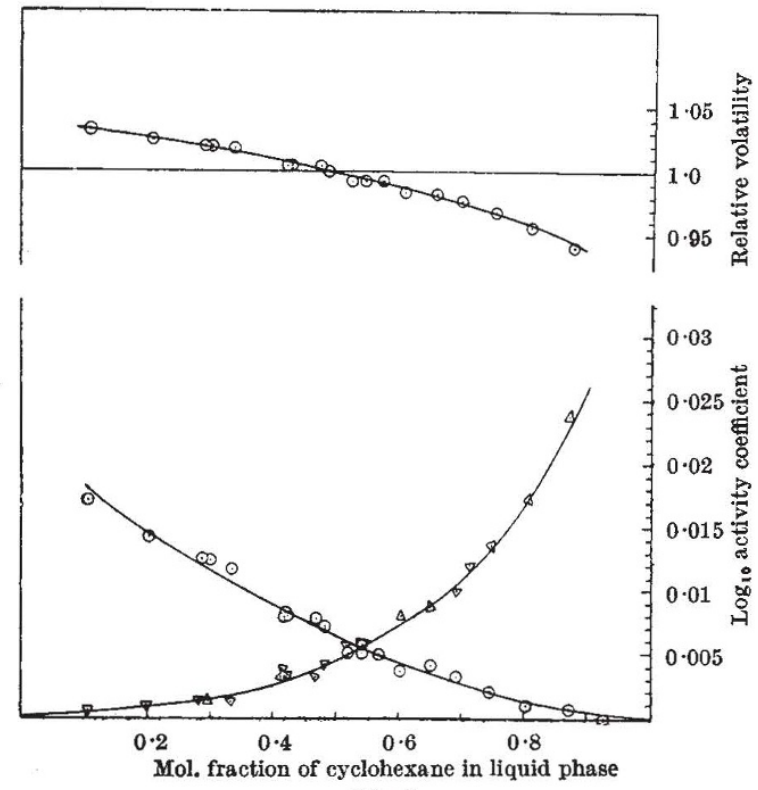

Fig. 2 